\title{
VISIONES REGIONALES DE LA LITERATURA PERUANA
}

(Conferencia en la Universidad Nacional del Santa: 18/12/2012)

\author{
Saniel E. Lozano Alvarado
}

\section{INTRODUCCIÓN}

Como lo afirmamos en la Introducción a nuestro libro "Literatura Regional de La Libertad" (2012), el estudio de la literatura peruana generalmente representó la visión de la metrópoli, de la ciudad capital, con el predominio de su enfoque historicista, panorámico y de síntesis, casi siempre insuficiente, incompleto y unilateral. Como contrapartida, la producción provinciana fue (y es) ignorada o vista con cierta indiferencia y mayormente se agotó o se agota en la curiosidad y, lo que es más grave, en la ignorancia o indiferencia, porque la mayoría de la gente, incluidos los sectores ilustrados, no se percatan de la producción o no le dan importancia. No obstante, en los últimos años la situación viene cambiando paulatina y considerablemente, debido, en parte, al incremento de autores y al volumen de su producción; a la calidad literaria de muchas producciones, como lo revelan varios reconocimientos y galardones de dimensión nacional; al afán de mostrar lo que cada pueblo produce; al deseo de afirmar y difundir los valores culturales de cada región o localidad; al propósito de contribuir a definir la tan anhelada y voceada identidad local y regional, en el contexto de la cultura nacional y en el horizonte más vasto de la cultura latinoamericana.

Resulta estimulante entonces comprobar cómo viene adquiriendo consistencia una saludable tendencia que fija su atención en las realizaciones de cada

1 Profesor de la Universidad Privada Antenor Orrego. Presidente de la Asociación Peruana de Literatura Infantil y Juvenil (APLIJ). Miembro de número de la Academia Peruana de Literatura Infantil y Juvenil. 
comunidad regional en un país tan vasto, complejo, plural, diverso y heterogéneo como el Perú. Claro que, de pronto, no se trata aún de un fenómeno integrado con sentido totalizador; pero tampoco se pueden pasar por alto los meritorios y serios trabajos de prestigiosos y esforzados académicos, investigadores e intelectuales, cuya obra acuciosa, exhaustiva, exploradora, emotiva y pujante, brota en diversos lugares de la patria. Lo repito, el "corpus" o universo de autores y obras que muestran el proceso literario-cultural de su respectiva región ya no se agota en una relación más o menos limitada; al contrario, es un proceso en continuo y vigoroso crecimiento y desarrollo, por lo que lo que aquí mostramos debe tomarse solo como ejemplo, como una simple muestra. Lo que sí hace falta es que las universidades, institutos de investigación y centros de formación docente se sacudan de su rutina repetitiva y de una indolente modorra y se pongan urgentemente al día con el registro, estudio y acceso a las expresiones de su respectivo entorno, pero no para sumirse en él, sino para desde allí comprender la vida, la aventura humana, el curso de la historia y el mundo, toda vez que leer verdaderamente literatura no es para reproducir contenidos, descubrir temas y formular moralejas. No es entretenerse con la trama de relatos o sacudirse y temblar con la carga sensitiva de los poemas. Leer literatura es esa otra manera de conocer el mundo, el hombre, la realidad, la tierra, la comunidad, la sociedad, a través de las tramas o historias de los textos que, por eso mismo no son sino signos o metáforas de una realidad objetiva o espiritual de la que se nutren y a la cual representan. Por eso mismo, de nada vale reproducir temas o argumentos, enumerar personajes, memorizar características, si, al final de cuentas, no se comprende que leer literatura es ir a un mundo de ficciones, pero no para quedarnos absorbidos allí, sino para volver a la vida superados, transformados y desarrollados, porque la literatura es fuerza e impulso de la creación, evolución y transformación personal y social. Lástima grande, eso sí, que en nuestro tiempo, cada vez sean menos los que leen y los pocos que leen leen poco y mal. Esta afirmación no es gratuita; es resultado de una comprobación diaria y cotidiana, porque hemos dejado de leer en forma habitual, distintiva y característica; en otras palabras, el libro se bate en retirada y ya casi nadie lee: en el hogar y la familia, en la sociedad y en los centros educativos, desde la escuela hasta la universidad; ya no leen los padres ni los familiares; ya no leen los profesores ni las autoridades. Y si no leen, pueden vivir seguramente en un mundo civilizado dotado de muchos productos y signos de modernidad, pero carente de sensibilidad, cultura y libertad. Esta es la realidad y éste es el reto. El problema se agrava por el riesgo de la extinción del libro físico, avasallado por el avance y predo- 
minio de la comunicación electrónica, según anuncian ciertos augures y profetas. Tal actitud, sin embargo, olvida que la lectura tiene diversos planos y significados, pues en lo etimológico significa e "legere"; es decir, ligar, unir, atar; en lo semántico es cosechar; en lo semiótico es descubrimiento de signos y sentidos; en lo neurológico es algo mental, cerebral, sanguíneo y oxigenante.

Por último, queremos precisar que nuestro trabajo no constituye un recuento de la intensa y variada producción literaria que se produce en las diversas regiones del país. Nuestra atención se centra principalmente en los estudios e investigaciones publicadas, acompañados por las referencias a determinadas antologías y compilaciones.

\section{ANTECEDENTES}

El replanteamiento en el estudio de la literatura peruana a partir de las visiones regionales no es nuevo. Tiene sus más lejanos antecedentes, primero, en la estupenda antología "La narración en el Perú", de Alberto Escobar (1956), publicada por primera vez hace ya más de medio siglo, y apuntaladas en 1986 por "Fiesta prohibida" o "Apuntes para una interpretación de la nueva poesía peruana 60 / 80" (1986), del consagrado poeta, investigador y antólogo Jesús Cabel Moscoso.

Asimismo, es justo destacar el enorme y trascendental esfuerzo y aporte a la cultura y a literatura peruana cumplido por Ricardo Virhuez Villafane, director de la "Revista Peruana de Literatura", que en sendos informes especiales presenta amplios panoramas sobre determinadas regiones del país, como "La ciudad vanguardista del lago", "La Libertad: tierra de poesía", "Chimbote: Mar de las letras”, etc.

En esta misma línea desempeña papel descollante la revista "Arteidea", que anima el editor, poeta y promotor cultural Jorge Luis Roncal.

Estas menciones se inscriben en el formidable antecedente que significó en su tiempo las revistas “Amauta”, de José Carlos Mariátegui, y “Colónida”, dirigida por Abraham Valdelomar.

\section{APORTES REGIONALES}

Pero volvamos a lo nuestro; a lo que nos congrega en este certamen, en cuyo reconocimiento debemos rendir nuestro homenaje a los autores, investigadores, críticos, editores, empeñados en mostrar los frutos intelectuales cosechados en las entrañas de su propio pueblo. Entonces nos encontramos con una 
relación de múltiples autores y obras, como la relación siguiente: "Poesía cuzqueña: Derrotero para una ubicación de la poesía cuzqueña contemporánea”, del formidable poeta e investigador Luis Nieto (1956), "Piedra sobre piedra" o Poesía cusqueña contemporánea, de Mario Pantoja (200) y "Nueva antología del Cusco", trabajo emprendido por la propia Municipalidad de la capital impe$\operatorname{rial}(2005)$.

En Puno nuestras primeras indagaciones nos conducen necesariamente al volumen "Poesía indigenista", de Manuel Suárez-Miraval, incluido en el exitoso "Festival del Libro Puneño", cuya fecha lamentablemente no la podemos precisar. No obstante, de época más reciente son los magníficos trabajos “Antología comentada de la poesía puneña" (2005), del notable escritor, crítico e investigador Feliciano Padilla, así como el importante volumen "10 años de literatura puneña" (2006), de Jorge Flores Aybar.

En el mismo ámbito de la sierra sureña ubicamos "Poetas representativos de Apurímac" (2008), del infatigable investigador Federico Latorre Ormachea, que también ha ampliado su quehacer al ámbito de la literatura de tradición oral, campo dentro del cual exhibe varios títulos.

Si ahora damos un salto a la Ciudad Blanca nos vamos a encontrar con los formidables libros: "Literatura arequipeña” (2003) y "Antología de la poesía arequipeña 1950-2000”, ambos del investigador Tito Cáceres Cuadros, sin obviar la ya distante selección de "El cuento arequipeño" de Vladimiro Bermejo (1958) y la antología de poesía arequipeña, de Jorge Cornejo Polar. En este mismo espacio del sur del país descubrimos la estupenda "Antología general del cuento en Tacna", siglos XIX y XX, del poeta, editor y promotor cultural Luis Alberto Calderón Albarracín (2009), gran animador y director de la revista literaria de poesía y narraciones breves "La cometa de papel", que ha alcanzado varios números.

Si del sur desplazamos la mirada al centro del país nos encontramos con la magnífica trilogía de la serie "Antología huanuqueña siglo XX", constituida por los volúmenes sobre narrativa, emprendida por Andrés Cloud y Mario Malpartida (1989), ensayo (A. Cloud, 1989) y poesía (del mismo A. Cloud, 1992). A esta serie debe agregarse "La literatura huanuqueña en debate: Nuevos aportes", de Rosa Mendoza de Malpartida (1989), "Cuentos huanuqueños: Narradores del XXI”, selección de Ramiro Razzo (2003) e incluso el volumen "Literatura tingalesa: cuentos y crónicas de Tingo María", selección de Hevert Laos Visag (2004). 
En Ica hay un nombre emblemático por su producción referida no solo al mencionado espacio, sino con una cobertura nacional mucho mayor. Se trata del citado Jesús Cabel, autor de los volúmenes "Lecturas iqueñas" (1987), "Memoria del sol: Nueva poesía iqueña" (1997), "Valdelomar: memoria y leyenda" (2003), "Arguedas: entre el fuego y el desierto. Estancia en Ica" (2007), entre otros valiosos e imprescindibles volúmenes.

Saltando al norte nos salen al paso trabajos que constituyen verdaderos hitos de la literatura regional, como: "Literatura de Tumbes", del Rigoberto Meza Chunga y "Hojas de mangle" o Literatura de Tumbes (2007), realizado en forma conjunta por Marco A. Cabrera Atoche y Wálter Flores Aguilar.

Bajando Tumbes, en la siguiente región destacan los trabajos: "Panorama de los poetas piuranos desde 1960", de Alberto Alarcón (1986), el "Estudio de la poética regional" de Piura, de Enrique Alamo y Wálter Navarro (1990); y la "Antología comentada de la expresión literaria contemporánea en la Región Grau”, de Sigifredo Burneo Sánchez (1992).

También un poco más acá, específicamente en Chiclayo, sobresale la figura de Luis Rivas Rivas, autor de la amplia y panorámica "La Literatura Lambayecana”, que se suma a la antología poética de Lambayeque que hace algunos años publicó David Céspedes Huamán.

Si ahora nos damos una vuelta por la región de Cajamarca, vamos a descubrir el perfil nítido de Luzmán Salas Salas, la figura que más ha explorado, investigado y rastreado la expresión literaria de tan importante región, como lo revelan sus libros: "Antología de la literatura infantil cajamarquina" (1981), "Poetas de Cajamarca" (1986), "Lecturas selectas sobre Cajamarca” (2003), "La prosa de los cajamarquinos" (2010), etc. Además, hay que considerar la revelación literaria de determinadas provincias de la misma región cajamarquina, debido al tesón y esfuerzo de otros definidos y decididos investigadores, creadores y escritores. Por ejemplo: "Contumazá, cuna de poetas”, de Víctor Angulo Camacho (2003), "Diamantes literarios contumacinos", de Francisco Deza Saldaña (2003), "Literatura cutervina", desde sus inicios - 1920, de Romel J. Avellaneda Montenegro (2005), "Poetas chotanos en Chota", de Estuardo Villanueva y Videlmo Núñez Tarrillo (2003). Precisamente, al hablar de Videlmo, hay que destacar su insistencia vocacional en el aliento y promoción de las letras de su provincia: Chota, como lo ratifica su antología "Otros ecos habitan en el jardín" (2009), que reúne voces de fines del siglo XX y comienzos de la nueva centuria. 
Específicamente sobre la región La Libertad hay un nombre egregio e imprescindible: Marco Antonio Corcuera, tenaz impulsor del formidable Concurso "Poeta Joven del Perú", poeta prolífico y fecundo y autor de históricas antologías: Poetas de La Libertad, Narradores de La Libertad y Ensayistas de La Libertad, todas publicadas a fines de los años 50.

Más limitados en el espacio, más localistas, más adheridos a la comarca liberteña son los libros: "Poetas de La Libertad" (1978), de Julio Galarreta González; "Santiago tierra de poetas", de Danilo Sánchez Lihón (1999), el breve pero representativo volumen "Ensayistas de Santiago de Chuco" (2005), de Bety Sánchez Layza (2005), así como los estudios publicados por Blasco Bazán Vera: "Literatura regional (del valle de Jequetepeque, 1991), "Literatura liberteña" (1999) y "Génesis de la literatura liberteña” (2005).

En todo este contexto, nosotros sumamos nuestro modesto aporte con los títulos: "Literatura infantil y juvenil de La Libertad" (1993), "Escritores de la región La Libertad" (2006), "Literatura regional de La Libertad" (2009 y "Literatura de Otuzco: las letras en mi comarca y en mi provincia” (2010). Títulos a los cuales debe agregarse estos otros libros: "La tierra encantada: Leyendas de La Libertad" (1989), "Historias a la luz del candil o Tradición oral de la región La Libertad" (2011), e incluso nuestros estudios específicos: "La vocación del amor en la poesía de María Negrón Ugarte” (1990), así como nuestra antología "Historia de un farol o César Vallejo en anécdotas" (2005), etc.

La última referencia sobre panoramas de las literatura regionales la constituye la "Antología literaria sanmartinense: autores contemporáneos" (s.a.), elaborada y producida por el Centro Cultural Rezistencia, de Tarapoto y cuyo principal recopilador ha sido Miuler Vásquez González.

La literatura ancashina es vista a través de varios enfoques y perspectivas, en cuyo conjunto podemos citar esta producción: "El rostro de la brisa: Chimbote en su literatura" (1992), de Saniel E. Lozano Alvarado, el primer estudio sobre la narración y la poesía chimbotana, limitada a comienzos de la segunda mitad del siglo XX y requerida de estudios que continúen la tarea hasta los tiempos contemporáneos.

Después citamos: "Territorio de la esperanza: Nueva poesía ancashina" (1989), de Jesús Cabel y Yehudi Collas Berrú; “Antología de la poesía chimbotana”, del disperso y autodidacta aunque empeñoso Víctor Unyén Velezmoro (2006); "Un río que no cesa: poesía amorosa de Ancash 1960-2000), de Ediciones Altazor; "Navegar en la lluvia: antología del cuento ancashino", de 
Ricardo Ayllón (2003), una de las voces más altas y representativas de nuestro proceso literario actual, quien también es autor de: "Invención en la bahía: 5 narradores chimbotanos" (2004: Ayllón, Morales, Rubio, Tamay, Tapia); "Cuentos del último navegante", antología del Grupo "Isla Blanca", de Gonzalo Pantigoso, reconocido poeta, narrador y crítico, que sin duda prestigia de manera especial a la Universidad Nacional del Santa y a las letras de esta región.

Pero, ya que de Ancash se trata, hay que remarcar la importante y prolífica producción de uno de los investigadores y catedráticos más importante de esta región. Nos referimos a la prestigiosa y fecunda figura del maestro César Angeles Caballero, infatigable estudioso de la literatura de "tierra adentro" y el autor que más ha investigado el proceso literario de varias regiones del país, como lo acreditan sus libros: "Literatura de Tacna" (1982), "Literatura del Callao" (2005), "Literatura de Huánuco" (2005), "Literatura de Pasco" (2007), además de sus volúmenes sobre la literatura de Ica, Ayacucho y Ancash.

\section{REFLEXIÓN Y PERSPECTIVAS FINALES}

Bueno, pero ¿qué sugiere esta relación cada vez más vasta y compleja de libros y autores en varias regiones del país? ¿Por qué el estudio de la literatura peruana ya no puede limitarse a los extraordinarios aportes que en su momento significaron los libros de Luis Alberto Sánchez, Augusto Tamayo Vargas, Alberto Tauro del Pino? Es indudable que el "corpus" literario peruano se ha desbordado hasta tornarse inabarcable. La literatura peruana ya no puede estar constituida solo por la visión metropolitana, sino tiene que plantearse desde las comarcas, provincias y regiones hacia el conjunto nacional.

Por otro lado, optar por la literatura regional, que a muchos incomoda, es otra vez actualizar la oposición cada vez más definida entre la modernidad y la tradición, entre el universalismo y el nacionalismo, o entre el nacionalismo y la localidad. En otros términos, se trata de nuevo de poner frente a frente los enfoques, conceptos y propuestas de escritores tan acreditados como Mario Vargas Llosa y Julio Cortázar, partidario de la eliminación de las fronteras locales y de las comarca e incluso de los nacionalismos, para optar por una visión global y universal de la cultura, ya que ése es el destino de la sociedad moderna; y por otro lado, significa sumirse transidos de evocación y nostalgia, llenos de espíritu provinciano, aldeano o parroquial, en la visión de la realidad desde el mirador andino y comunero, que tan entrañablemente definía a nuestro José María 
Arguedas, quien tampoco pudo superar el conflicto entre el mundo andino y el mundo occidental. En efecto, exaltar la imposición del cóndor (andino, cordillerano, nativo) sobre el toro de las corridas hispanas en "Yawar fiesta" ¿no significa reconocer la superioridad de la cultura andina, pero dejándola intacta en su postración? O al contrario, ¿debemos optar por lo moderno, pero a costa de cancelar todo vestigio ancestral de donde procede la nación?

Por otro lado, si ubicamos el problema en el contexto de la globalización y la modernidad, no podemos verlos simplemente como procesos que vienen de afuera como oleadas que barren y borran todo vestigio local o nacional. Es verdad que los pueblos ya no pueden vivir aislados, pero la globalización, como proceso integrador tiene que ser enfocado en su totalidad e integridad, como un proceso que no se limita a las manifestaciones económicas, industriales o financieras, sino como una realización conjunta en la que las naciones reciben pero también aportan recíprocamente; por tanto, nuestros pueblos no pueden ser simplemente receptores, dependientes o consumidores; al contrario, al menos en el caso de la cultura peruana, debemos tener la firme convicción de que también podemos aportar creadoramente al mundo; pero eso lo podemos hacer no escondiendo o ignorando lo nuestro, devaluándolo, sino mostrándolo, difundiéndolo y propagándolo. El reto es mucho mayor para sociedades y culturas tan heterogéneas como la peruana; pero allí mismo radica su riqueza y complejidad.

No podemos perder de vista que la modernidad es un monstruo de dos caras: para los países desarrollados significa innovar, crear y producir; para nosotros, comprar, consumir y adquirir productos. La literatura, como parte de la cultura, tampoco puede ser barrida, eliminada o arrinconada. Optar por la literatura regional es empezar a fijar la atención en lo nuestro, base de nuestro reconocimiento y de nuestra identidad, sin oponernos a la globalización, sino considerándola como un proceso complejo que debe enriquecerse con el aporte de todas las culturas. Pero para eso debemos tender puentes con la producción intelectual, que no puede perderse en la indiferencia y la rutina. Tenemos que recuperar el espacio que siempre debe ocupar el libro y la lectura y dejar de ser analfabetos funcionales.

Universidad Nacional del Santa Chimbote, 18 de diciembre del 2012. 